\title{
Ionic Liquids and Deep Eutectic Solvents in Natural Products Research: Mixtures of Solids as Extraction Solvents
}

\author{
Yuntao Dai, ${ }^{\dagger}$ Jaap van Spronsen, ${ }^{\ddagger}$ Geert-Jan Witkamp, ${ }^{\ddagger}$ Robert Verpoorte, ${ }^{\dagger}$ and Young Hae Choi ${ }^{*},^{\dagger}$ \\ ${ }^{\dagger}$ Natural Products Laboratory, Institute of Biology, Leiden University, 2300 RA Leiden, The Netherlands \\ ${ }^{\ddagger}$ Department of Biotechnology, Delft University of Technology, Delft, The Netherlands
}

Supporting Information

ABSTRACT: Mixtures of solid chemicals may become liquid under certain conditions. These liquids are characterized by the formation of strong ionic (ionic liquids) or hydrogen bonds (deep eutectic solvents). Due to their extremely low vapor pressure, they are now widely used in polymer chemistry and synthetic organic chemistry, yet little attention has been paid to their use as extraction solvents of natural products. This review summarizes the preparation of ionic liquids and deep eutectic solvents with natural product components and recent progress in their applications to the extraction and analysis of natural products as well as the recovery of extracted compounds from their extracts. Additionally, various factors affecting extraction features of ionic liquids and deep eutectic solvents, as well as potential useful technologies including microwave and ultrasound to increase the extraction efficiency, are discussed.

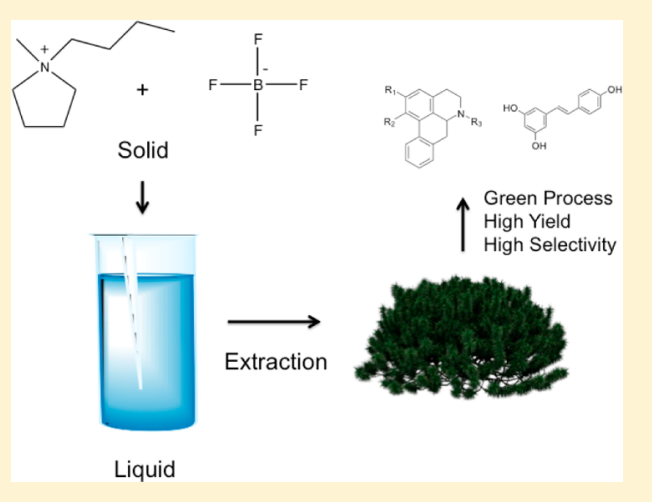

\section{INTRODUCTION}

Ionic liquids (ILs) are mixtures of low melting point $\left(<100{ }^{\circ} \mathrm{C}\right)$ organic salts composed of organic cations and organic or inorganic anions. The well-accepted definition of room-temperature ionic liquids (RTILs) is "the salt that has a melting point lower than ambient temperature". ${ }^{1}$ Deep eutectic solvents (DESs) are a new class of solvents obtained by mixing solid compounds that are not necessarily salts, such as choline chloride and sugar, obtaining a eutectic mixture with a melting point that is much lower than that of the individual components. ${ }^{2}$ In most cases, ILs have an asymmetrically substituted cation (e.g., imidazolium, pyrrolidinium, pyridinium, ammonium, phosphonium) and a variety of anions, especially halogen-based anions (e.g., $[\mathrm{Cl}],[\mathrm{Br}],[\mathrm{I}],\left[\mathrm{BF}_{4}\right],\left[\mathrm{AlCl}_{4}\right],\left[\mathrm{PF}_{6}\right]$ ) (see Table S1, Supporting Information). To overcome the potential toxicity of halogen anion-containing ILs, ${ }^{3,4}$ biomaterial-derived products such as organic acids, amino acids, amines, or sugars have been used to create a new, safer type of ILs known as "bio-ILs" or "green ILs". ${ }^{5-7}$ There are also reports of DESs made up of various natural products that fit into this category. ${ }^{2,8-10}$

Interest in ILs stems from this potential application as "green solvents" based on, perhaps, their most important feature: nearly complete nonvolatility at ambient condition if compared with volatile organic solvents. ${ }^{1}$ Apart from this, ILs have many attractive physicochemical properties, such as chemical and thermal stability, nonflammability, high conductivity, and a good solubilizing capacity of a number of organic compounds. ${ }^{1}$ Both the anion and the length of the $n$-alkyl chain of the cation of an IL affect its physical properties; ${ }^{11}$ as a result, its viscosity and polarity, for example, can be tuned by changing the cationanion combination. Thus, ILs are termed "tailor-made solvents" and offer a huge potential for practical applications. ${ }^{12}$ The same properties are also observed in DESs, converting both these types of liquids into ideal substitutes of conventional organic solvents.

Recently, various applications of ILs and DESs have been reported. In the case of natural product analysis, ILs have been used as a stationary phase, as summarized by Tang et al., ${ }^{13}$ or a mobile phase additive in chromatography. ${ }^{14-16}$ Ionic liquids have been used for the extraction of compounds of diverse polarity from aqueous samples, such as organic acids, ${ }^{17,18}$ amino acids, ${ }^{19}$ phenols, $^{20,21}$ and alkaloids. ${ }^{22,23}$ For solid materials such as herbal biomass, ILs, in combination with extraction technologies, such as microwave ${ }^{24,25}$ and ultrasonic treatment, ${ }^{26}$ have been employed successfully to extract diverse kinds of natural products, such as alkaloids, carbohydrates, phenolic compounds, and sesquiterpenes. After extraction, the resulting extracts are generally diluted with water or organic solvents for further HPLC analysis, ${ }^{25}$ and volatile compounds are evaporated for GC analysis. ${ }^{27}$ The lack of volatility of ILs makes it nearly impossible to concentrate directly and isolate nonvolatile compounds from them, but several methods have been successfully used to resolve this problem, including the use of supercritical $\mathrm{CO}_{2}$ extraction, ${ }^{28}$ with the addition of antisolvents, ${ }^{29}$ back extraction, ${ }^{17}$ and column chromatography. ${ }^{30}$

Depending on the structure of the cations and anions, ILs with different physical properties have been obtained. This means that it is possible to design an optimal IL for a specific compound, therefore allowing specific "object-oriented" or "task-specific" ILs to be prepared. For example, some ILs with larger $\pi$ values are expected to solubilize many $\pi$-conjugated

Received: January 18, 2013

Published: November 4, 2013 
organic substances. ${ }^{22,31}$ Also, ILs based on simple natural compounds can be synthesized for the extraction of certain kinds of natural products, such as amino acid-based ionic liquids (AAILs) that display enantioselectivity in the extraction of amino acids ${ }^{19}$ and $\mathrm{Gly}-\mathrm{ChCl}$, which has been used to extract glycerol from biofuel. ${ }^{32}$ Similarly, the application of other types of ILs and DESs in the extraction of natural products should be investigated further in terms of their physical properties.

In the case of natural products, these solvents offer the prospect of being novel extraction methods, with a high efficiency and offering a high yield of a great variety of compounds, given the high dissolving power of some ILs. ${ }^{24}$ There are also other great advantages of ILs over conventional organic solvents. For instance, some ILs have been used to extract both essential oil compounds and polar compounds in the same step. ${ }^{33}$ However, because of their high viscosity, most ILs are used as diluted aqueous solutions. ${ }^{25}$ The extraction efficiency of other types of low-viscosity ILs, such as ILs made of natural products that have been developed, requires further investigation, since there are few reports of their application.

This review covers major aspects of ILs and DESs that are related to natural products, including the synthesis of "green" ILs and DESs with natural products, their properties, and applications to natural product extraction, along with the combined use of ILs with other technologies, methods for the analysis of IL extracts, and the recovery of compounds from these extracts. Factors affecting the extraction efficiency of ILs and the problems and challenges that have arisen from the above applications are also discussed.

\section{PREPARATION OF IONIC LIQUIDS AND DEEP EUTECTIC SOLVENTS AND THEIR PROPERTIES}

Preparation of Ionic Liquids with Natural Products. Recently, there has been a growing consensus on the acceptance of ILs as greener alternatives to volatile organic solvents, mainly due to their negligible vapor pressure. However, they fall short of complying with the 12 principles of green chemistry, casting doubt on the legitimacy of this claim. ${ }^{34}$ Commonly used ILs based on halogenated anions and their derivatives have low melting points, but their applications are obviously limited by toxicological, ecological, and economic issues. $^{2}$ ILs with an imidazolium cation are synthetic chemicals, even though some of these use amino acids as starting materials. ${ }^{35}$ Furthermore, some of these imidazolium-based ILs are also toxic., ${ }^{4,19}$ In addition, some types of biorenewable natural products, including organic acids, sugars and artificial sweeteners, and amino acids, have been applied to prepare "green" ILs and DESs. ${ }^{36}$

Organic Acids. A series of ILs composed of choline and organic acids have been reported. ${ }^{6}$ These ILs are prepared via a two-step anion-exchange reaction. On the other hand, mixtures of organic acids and choline chloride (Table 1) have also been used to form DESs by heating. ${ }^{10}$

Sugars and Sweeteners. Sugars and sweeteners have also been considered for the preparation of green ILs. Fructose was mainly used as the starting material of a new class of ILs that exhibited tunable solvent properties much like conventional imidazole-based ILs. The process, however, was not simple and included some toxic chemicals even though the starting material was green. ${ }^{37}$ Saccharin $[\mathrm{Sac}$ ] and acesulfame [Ace] are used widely in foodstuffs as non-nutritive sweeteners, and they have well-established toxicological profiles, compared with the common anions in ILs, $[\mathrm{Cl}]$ and $\left[\mathrm{BF}_{4}\right]$. A series of ILs made of [Sac] and [Ace] with common organic cations have been prepared via metathesis. ${ }^{38}$ Two green ILs, [Ch][Ace] and $[\mathrm{Ch}][\mathrm{Sac}]$, have been synthesized. The ecotoxicity of these ILs in aqueous solution is very low in comparison to other types of ILs. $^{39}$

Amino Acids (AAs). Ionic liquids based on amino acids may be natural "designer solvents" due to their zwitterionic structure and the adjustable properties achieved by introducing a functional group(s) in both carboxylic acid and amino groups. AAILs with amino acids as cations have been synthesized through a one-step acidification. ${ }^{35}$ A series of ILs with low melting points have been obtained successfully from amino acid esters, through a one-step esterification and the metathesis method. ${ }^{35}$ The "designer solvent" character and the biodegradability of these ILs are potentially enhanced. AAILs with other types of cations have been developed, such as $[\mathrm{TBP}][\mathrm{AA}] \mathrm{s}$, made of tetrabutylphosphonium (TBP) and amino acids, ${ }^{40}$ and $[\mathrm{TAA}][\mathrm{AA}] \mathrm{s}$, composed of a tetraalkylammonium (TAA) cation and an amino acid. ${ }^{41}$ With the objective of increasing the "greenness" level, a family of novel ILs with [Sac] and $\left[\mathrm{NO}_{3}\right]$ as anions and amino acids esters as cations have been synthesized applying the metathesis method. ${ }^{5}$ The natural products choline chloride and proline, ${ }^{7}$ choline hydroxide, and five different amino acids (glycine, alanine, phenylalanine, threonine, and histidine $)^{42}$ have been used to synthesize natural AAILs. Choline, amino acids, $[\mathrm{Sac}]$, and $\left[\mathrm{NO}_{3}\right]$ are nontoxic, are biodegradable, and have pharmaceutically acceptable properties, so that the resulting ILs could be qualified as "fully green solvents". In addition, it is noteworthy that these AAILs are also called "chiral ionic liquids" (CILs) and "functional or task-specific ILs", because they conserve the stereogenic center present in the amino acids. ${ }^{5,35}$

Properties of "Green" Ionic Liquids. The glass transition temperature $\left(T_{\mathrm{g}}\right)$ or melting temperature $\left(T_{\mathrm{m}}\right)$, viscosity, thermal stability, and polarity are important properties for the application of ILs as extraction solvents; they are summarized in Table S2 (Supporting Information). For [Emim][AA]s and $[\mathrm{TBP}][\mathrm{AA}] \mathrm{s}$, an increase of the alkyl side-chain length coincides with a gradual increase of $T_{\mathrm{g}}$ due to an increase of the van der Waals forces between alkyl side chains: [Emim][Gly $]\left(-65{ }^{\circ} \mathrm{C}\right)<[\mathrm{Emim}][\mathrm{Ala}]\left(-57^{\circ} \mathrm{C}\right)<[\mathrm{Emim}][\mathrm{Val}]$ $\left(-52{ }^{\circ} \mathrm{C}\right) .{ }^{5}$ ILs made of choline and organic acids have both $T_{\mathrm{g}}$ (from -6 to $-72{ }^{\circ} \mathrm{C}$ ) and $T_{\mathrm{m}}$ (from 25 to $131{ }^{\circ} \mathrm{C}$ ). ${ }^{8}$ [AAE] $[\mathrm{Sac}]$ ILs have a higher $T_{\mathrm{g}}$, a much higher viscosity, but better thermal stability than the corresponding $[\mathrm{AAE}]\left[\mathrm{NO}_{3}\right]^{5}$ There is a linear relationship between the $T_{\mathrm{g}}$ and viscosity for $[\mathrm{TBP}][\mathrm{AA}] \mathrm{s}^{40}$ The viscosity of $[\mathrm{AAE}]\left[\mathrm{NO}_{3}\right]$ is similar to conventional imidazolium ILs. Among AAILs with the same amino acid as the anion and [Emim], [TBP], or [TAA] as the cation, [TAA]-based AAILs are the least viscous. This can be explained by the lower molecular weight and higher flexibility of the alkyl chain of [TAA] as compared to the [TBP] cation. ${ }^{41}$ The lower viscosity of AAILs with [TAA] than with [Emim] indicates that [TAA]-based AAILs may be promising solvents as extraction media for natural products. In terms of their thermal stability, all the AAILs obtained are stable up to 150 or $200{ }^{\circ} \mathrm{C}$, a little below imidazolium-based ILs, but clearly above the minimum $100{ }^{\circ} \mathrm{C}$ requirement described by Wasserscheid and colleagues for chiral ILs. ${ }^{43}[\mathrm{TBP}][\mathrm{AA}] \mathrm{s}$ have a higher decomposition temperature $\left(T_{\mathrm{m}}\right)\left(>300{ }^{\circ} \mathrm{C}\right)$ than [Emim]$[\mathrm{AA}] \mathrm{s}\left(170\right.$ to $\left.200{ }^{\circ} \mathrm{C}\right)$ and $[\mathrm{TAA}][\mathrm{AA}] \mathrm{s} .{ }^{40}$ The properties of AAILs depend greatly on the side groups involved. ${ }^{44}$ The AAILs composed of an amino acid with some functional groups 
Table 1. Composition and Melting Points $\left(T_{\mathrm{m}}\right)$ of Deep Eutectic Solvents

\begin{tabular}{|c|c|c|c|c|c|c|c|c|c|}
\hline \multicolumn{2}{|c|}{ component } & molar ratio & $T_{\mathrm{m}} /{ }^{\circ} \mathrm{C}$ & ref & \multicolumn{2}{|c|}{ component } & \multirow[t]{2}{*}{ molar ratio } & \multirow[t]{2}{*}{$T_{\mathrm{m}} /{ }^{\circ} \mathrm{C}$} & \multirow[t]{2}{*}{ ref } \\
\hline Organic Acid & & & & & Sugar & & & & \\
\hline adipic acid & choline chloride & $1: 1$ & 153 & 2 & sucrose & malonic acid & $6: 4^{a}$ & 80 & 48 \\
\hline benzoic acid & choline chloride & $2: 1$ & 122 & 2 & & & & & \\
\hline citric acid & choline chloride & & 149 & 2 & glucose & dimethylurea & $3: 7^{a}$ & 80 & 48 \\
\hline malonic acid & choline chloride & $1: 1$ & 135 & 2 & mannose & dimethylurea & $4: 6^{a}$ & 80 & 48 \\
\hline oxalic acid & choline chloride & $1: 1$ & 190 & 2 & fructose & dimethylurea & $4: 6^{a}$ & 70 & 48 \\
\hline phenylacetic acid & choline chloride & $2: 1$ & 77 & 2 & isomaltose & dimethylurea & $4: 6^{a}$ & 90 & 48 \\
\hline phenylpropionic & choline chloride & $2: 1$ & 48 & 2 & glucose & 4-methyl-imidazole & $2: 8^{a}$ & 50 & 48 \\
\hline acid & & & & & mannose & 4-methyl-imidazole & $2: 8^{a}$ & 50 & 48 \\
\hline succinic acid & choline chloride & $1: 1$ & 185 & 2 & fructose & 4-methyl-imidazole & $2: 8^{a}$ & 50 & 48 \\
\hline tricarballylic acid & choline chloride & & 159 & 2 & sucrose & 4-methyl-imidazole & $4: 6^{a}$ & 70 & 48 \\
\hline citric acid & dimethylurea & $4: 6^{a}$ & 65 & 9 & isomaltose & 4-methyl-imidazole & $3: 7^{a}$ & 70 & 48 \\
\hline tartaric acid & dimethylurea & $3: 7^{a}$ & 70 & 33 & glucosamine & 4-methyl-imidazole & $3: 7^{a}$ & 50 & 48 \\
\hline citric acid & choline chloride & $1: 2 ; 1: 3$ & $b$ & 10 & glucose & pyrazole & $5: 5^{a}$ & 80 & 48 \\
\hline malic acid & choline chloride & $1: 1 ; 1: 2 ; 1: 3$ & $b$ & 10 & mannose & pyrazole & $4: 6^{a}$ & 50 & 48 \\
\hline maleic acid & choline chloride & $1: 1 ; 1: 2 ; 1: 3$ & $b$ & 10 & fructose & pyrazole & $5: 5^{a}$ & 70 & 48 \\
\hline aconitic acid & choline chloride & $1: 1$ & $b$ & 10 & sucrose & pyrazole & $4: 6^{a}$ & 60 & 48 \\
\hline Polyalcohol & & & & & isomaltose & pyrazole & $5: 5^{a}$ & 70 & 48 \\
\hline sorbitol & urea $+\mathrm{NH}_{4} \mathrm{Cl}$ & $7: 2: 1^{a}$ & 67 & 9 & glucosamine & pyrazole & $1: 9^{a}$ & 90 & 48 \\
\hline sorbitol & dimethylurea & $4: 6^{a}$ & 77 & 9 & glucose & guanidinium $\mathrm{HCl}$ & $4: 6^{a}$ & 70 & 48 \\
\hline glycerol & choline chloride & $3: 1$ & 20 & 49 & mannose & guanidinium $\mathrm{HCl}$ & $4: 6^{a}$ & 80 & 48 \\
\hline glycerol & choline chloride & $2: 1$ & 23 & 50 & fructose & guanidinium $\mathrm{HCl}$ & $4: 6^{a}$ & 70 & 48 \\
\hline sorbitol & urea & $5: 5^{a}$ & 70 & 48 & isomaltose & guanidinium $\mathrm{HCl}$ & $4: 6^{a}$ & 80 & 48 \\
\hline sorbitol & choline chloride & $4: 6^{a}$ & 70 & 48 & fructose & dimethylurea & $7: 3^{a}$ & 71 & 46 \\
\hline sorbitol & imidazole & $3: 7^{a}$ & 80 & 48 & mannose & dimethylurea & $3: 7^{a}$ & 75 & 46 \\
\hline sorbitol & 4-methyl-imidazole & $2: 8^{a}$ & 50 & 48 & glucose & malic acid & $1: 1$ & $b$ & 10 \\
\hline sorbitol & pyrazole & $3: 7^{a}$ & 60 & 48 & fructose & malic acid & $1: 1$ & $b$ & 10 \\
\hline sorbitol & guanidinium $\mathrm{HCl}$ & & $b$ & 48 & sucrose & malic acid & $1: 1$ & $b$ & 10 \\
\hline sorbitol & dimethylurea $+\mathrm{NH}_{4} \mathrm{Cl}$ & $7: 2: 1^{a}$ & 67 & 46 & glucose & citric acid & $1: 2$ & $b$ & 10 \\
\hline Sugar & & & & & sucrose & citric acid & $1: 1$ & $b$ & 10 \\
\hline fructose & urea & $6: 4^{a}$ & 65 & 9 & trehalose & citric acid & $2: 1$ & $b$ & 10 \\
\hline glucose & urea $+\mathrm{CaCl}_{2}$ & $5: 4: 1^{a}$ & 75 & 9 & glucose & fructose & $1: 1: 1$ & $b$ & 10 \\
\hline maltose & dimethylurea $+\mathrm{NH}_{4} \mathrm{Cl}$ & $5: 4: 1^{a}$ & 73 & 9 & Amine & & & & \\
\hline mannose & dimethylurea & $3: 7^{a}$ & 75 & 9 & urea & choline chloride & $2: 1$ & 134 & 8 \\
\hline$\alpha$-cyclodextrin & dimethylurea & $3: 7^{a}$ & 77 & 9 & methyl urea & choline chloride & $2: 1$ & 93 & 8 \\
\hline glucose & choline chloride & $4: 6^{a}$ & 80 & 48 & 1,3-dimethyl urea & choline chloride & $2: 1$ & 102 & 8 \\
\hline mannose & choline chloride & $4: 6^{a}$ & 50 & 48 & 1,1-dimethyl urea & choline chloride & $2: 1$ & 180 & 8 \\
\hline fructose & choline chloride & $4: 6^{a}$ & 70 & 48 & thiourea & choline chloride & $2: 1$ & 175 & 8 \\
\hline sucrose & choline chloride & $5: 5^{a}$ & 80 & 48 & acetamine & choline chloride & $2: 1$ & 80 & 8 \\
\hline isomaltose & choline chloride & $4: 6^{a}$ & 90 & 48 & benamide & choline chloride & $2: 1$ & 129 & 8 \\
\hline glucosamine & choline chloride & $1: 9^{a}$ & 100 & 48 & tetramethyl urea & choline chloride & $2: 1$ & -1 & 8 \\
\hline mannose & malonic acid & $5: 5^{a}$ & 90 & 48 & Amino Acid & & & & \\
\hline fructose & malonic acid & $7: 3^{a}$ & 100 & 48 & proline & citric acid & $1: 1 ; 2: 1 ; 3: 1$ & $b$ & 10 \\
\hline
\end{tabular}

such as a hydrogen-bonding group $\left(-\mathrm{OH},-\mathrm{NH}_{2},-\mathrm{COOH}\right)$, a charged group, or an aromatic ring exhibit a high $T_{\mathrm{g}}$ or $T_{\mathrm{m}}$ and high viscosity resulting from the additional interactions among ions, such as hydrogen bonding, stacking, and electrostatic interaction. Esterification reduces the amount of hydrogen bonding, resulting in a significant decrease in the $T_{\mathrm{m}}$ and viscosity of the salts. The $T_{\mathrm{m}}$ decreases to $-17{ }^{\circ} \mathrm{C}$ for $\left[\mathrm{AlaC}_{2}\right]\left[\mathrm{NO}_{3}\right]$ from $159{ }^{\circ} \mathrm{C}$ for $[\mathrm{Ala}]\left[\mathrm{NO}_{3}\right] .{ }^{35}$
Polarity is another important property of ILs, because the solubility of the solute, their miscibility with other solvents, and even their extraction ability are influenced by their polarity. Compared to general ILs, AAILs have a stronger hydrogenbond basicity, equivalent hydrogen-bond acidity, and equivalent dipolarity. The $\beta$-parameter, hydrogen-bonding basicity, introduced by Kamlet and Taft, has been established as a measure of the hydrogen-bond accepting ability of anions. ${ }^{45}$ 
$[$ Emim $][\mathrm{AA}] \mathrm{s}$ exhibit strong hydrogen-bond basicity $(\beta$ between 0.88 and 1.38), above $[\mathrm{Bmim}][\mathrm{Cl}](\beta=0.95)$, which is the IL precisely chosen for its high $\beta$ values. ${ }^{44}$ ILs made of choline and an organic acid also have a polarity similar to $[\mathrm{Bmim}][\mathrm{Cl}] .^{6}$ Thus, $[\mathrm{Emim}][\mathrm{AA}] \mathrm{s}$ and ILs made of organic acid and choline are expected to be polar solvents for scarcely soluble compounds.

Preparation of Deep Eutectic Solvents. Different kinds of natural products such as organic acids, sugars, polyalcohols, amines, and amino acids have been used to prepare DESs (Table 1). Compared with ILs, the preparation methods of DESs are simple, since they involve only stirring at room temperature or heating to $100{ }^{\circ} \mathrm{C}$. The preparation temperature and even the $T_{\mathrm{m}}$ of DESs depend on their composition. Abbott and co-workers have reported that mixtures of urea or organic acids with quaternary ammonium salts could become liquid when heated to $80-100{ }^{\circ} \mathrm{C}^{2,8}$ The König group has extended the range of DESs, including sugar-urea/dimethyl urea, polyalcohol-dimethyl urea, organic acid-dimethyl urea, ${ }^{9,46}$ L-carnitine-urea, ${ }^{47}$ sugar-choline chloride, and sugar-malonic acid. $^{48}$ These DESs may also include salts with a chloride ion, such as $\mathrm{CaCl}_{2}, \mathrm{NH}_{4} \mathrm{Cl}$, and $\mathrm{NaCl}$. They have a $T_{\mathrm{m}}$ in the range $50-100{ }^{\circ} \mathrm{C}$, mostly around $70{ }^{\circ} \mathrm{C}$, and some are stable at $95^{\circ} \mathrm{C}$ for $4 \mathrm{~h}$ without any evident decomposition, which supports their use as extraction solvents. DESs can also be formed between glycerol and choline chloride in different molar ratios, 3:1 $1^{49}$ or $1: 1 / 2: 1 .^{50,51}$ Meanwhile, Gutiérrez et al. ${ }^{52}$ have found that DESs can also be made by freeze-drying aqueous solutions, such as $\mathrm{U}-\mathrm{ChCl}(2: 1)$ and Gly- $\mathrm{ChCl}(2: 1) .{ }^{33}$ The freeze-drying method allows the incorporation of bacteria into the DESs in the pure state, ${ }^{53}$ allowing their application in biotransformations.

Natural products are a plentiful and ideal source of IL and DES components due to their enormous chemical diversity, biodegradability, sustainability, and pharmaceutically acceptable toxicity profile. Our group has introduced the term natural deep eutectic solvents (NADES) for these liquids, which extends the composition of DESs and ILs to natural products, such as citric acid and proline. ${ }^{10}$ In addition, the hypothesis of the existence of NADES in organisms could account for many biological processes that cannot be explained otherwise by the theory that limits the liquid media in organisms to water and lipids.

Properties of Deep Eutectic Solvents. Similarly to ILs, DESs are characterized by a high viscosity that can be $20-1000$ times above that of water at room temperature. ${ }^{33,54}$ Designing DESs with low viscosity is very desirable. The viscosity of DESs is inversely proportional to temperature. ${ }^{2,8}$ Most DESs have $T_{\mathrm{m}}$ above $50{ }^{\circ} \mathrm{C}$ (Table 1). In the case of DESs made of urea and quaternary ammonium, it has been found that the amides with the greatest ability to form hydrogen bonds (i.e., urea and thiourea) exhibit the largest depression in $T_{\mathrm{m}}{ }^{8}$ In the case of cations, as the symmetry of the cation used decreases, so does the $T_{\mathrm{m}}$ of the mixtures, similarly to ILs. The charge delocalization that occurs through hydrogen bonding between the halide anion and the hydrogen-donor moiety is responsible for the decrease in the $T_{\mathrm{m}}$ of the mixture, as compared to the $T_{\mathrm{m}}$ of the individual component. DESs made of choline salts with quaternary ammonium are highly conductive, confirming the presence of anionic species in the liquid that can move independently. ${ }^{8}$ The conductivity of DESs made of organic acids and choline chloride is in the range $0.1-10 \mathrm{mS} \mathrm{cm}{ }^{-1}$, similar to imidazolium-based ILs and DESs made of urea and choline chloride as well as their derivatives. ${ }^{8}$ In general, conductivity increases significantly with temperature. ${ }^{2,8}$ These data and their relationship with temperature are important to guide their applications.

\section{EXTRACTION OF NATURAL PRODUCTS WITH IONIC LIQUIDS AND DEEP EUTECTIC SOLVENTS}

Extraction of Natural Products with ILs and DESs. Diverse ILs have been tested for their aptitude to extract compounds from natural products covering the whole range of polarity such as phenolic compounds, alkaloids, essential oil components, lignins, and carbohydrates (Table 2). Most ILs are used in the form of an aqueous solution because of their high viscosity in pure state.

Phenolic Compounds. The IL-based microwave-assisted extraction (ILMAE) technique was first developed to extract different kinds of phenolic compounds. ${ }^{25}$ The structure of IL components plays an important role in extraction. In this case, the efficiency has proven to be anion-dependent, with $[\mathrm{Bmim}][\mathrm{Br}]$ being the best choice among the other ILs tested for the extraction of phenolic compounds such as transresveratrol (1), ${ }^{25}$ gallic acid (2), ellagic acid (3), quercetin (4), ${ }^{31}$ and rutin $(5) .{ }^{55}$ This can be attributed to its strong solvatation power and its multiple interactions, especially $\mathrm{H}$ bonding, polarity, $\pi-\pi, \mathrm{n}-\pi$, and ionic/charge-charge. ${ }^{56,57}$ On the other hand, for phenolic compounds with fewer hydroxy groups, such as magnolol (6), honokiol (7), quercetin (4), and trans-resveratrol (1), ILs with $\left[\mathrm{BF}_{4}\right]$ showed a high extraction ability, ${ }^{25,58}$ and [Bmim][TSO] exhibited a high extraction efficiency presumably because of the extra aromatic system. ${ }^{55}$

The parameters that are generally used in an extraction process with ILs are the following: a concentration of 2.0-3.0 $\mathrm{mol} / \mathrm{L}$, a 1:30-1:20 ratio for solid/liquid extractions, and a temperature range of $60-70{ }^{\circ} \mathrm{C}$. Additionally, the $\mathrm{pH}$ value of the solution may also affect the extraction efficiency. ${ }^{58}$

Alkaloids. The extraction of alkaloids is structure-dependent, and interactions such as $\mathrm{H}$-bonding, $\mathrm{n}-\pi$, and ionic/chargecharge are the driving forces. $[\mathrm{Bmim}]\left[\mathrm{BF}_{4}\right]$ showed efficient extraction ability for piperine $(8)^{26}$ and phenolic alkaloids [liensine (9), isoliensine (10), neferine (11), fangchinoline (12), and tetrandrine $(\mathbf{1 3})],,^{59,60}$ while $[\mathrm{Hmim}][\mathrm{Br}]$ exhibited ca. $40 \%$ higher extraction ability than $[\mathrm{Bmim}]\left[\mathrm{BF}_{4}\right]$ for $\mathrm{N}$-nornuciferine (14), $\mathrm{O}$-nornuciferine (15), and nuciferine (16). ${ }^{61}$ The extraction of alkaloids thus depends on both the kind of ILs and the structure of the compounds being purified; the extraction method should also be taken into account. For example, $[\mathrm{Hmim}]\left[\mathrm{BF}_{4}\right]$ and $[\mathrm{Bmim}]\left[\mathrm{BF}_{4}\right]$ reached the same extraction efficiency for these three phenolic alkaloids $(14,15)$ in ILMAE, ${ }^{61}$ while the extraction ability of $\left[\mathrm{Bmim}^{2}\left[\mathrm{BF}_{4}\right]\right.$ was $80 \%$ higher than that of $[\mathrm{Hmim}]\left[\mathrm{BF}_{4}\right]$ with ionic liquid-based ultrasonic-assisted extraction (ILUAE). ${ }^{26}$ This means that in ILUAE the viscosity of the ILs has a big influence on the extraction efficiency, while the high temperature in ILMAE decreases the viscosity differences between ILs caused by the alkyl chain length. As for the extraction parameters, the important and generally measured ones are the concentration of ILs (1.0-2.0 mol/L), solid/liquid ratio (1:30-1:10), and an extraction time of 60-90 s for ILMAE and $30 \mathrm{~min}$ for ILUAE.

Essential Oil Components. Most essential oil components are sensitive to high temperatures and will degrade, causing undesirable effects in the properties of the oil. Shortening the general distillation time is a good way of avoiding the damage caused by high temperature. ILMAE can provide a great advantage, as it shortens the required extraction time significantly (from $2 \mathrm{~h}$ to $15 \mathrm{~min}$ ). This is because the microwave 
पू

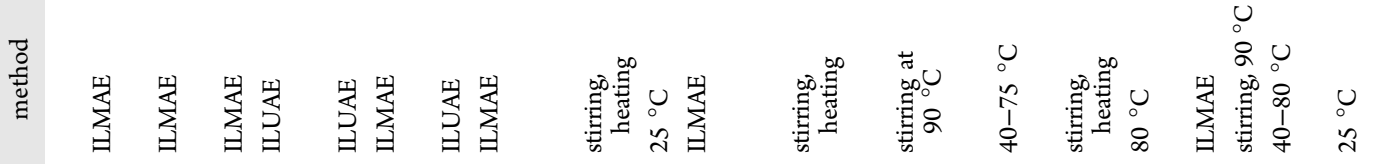

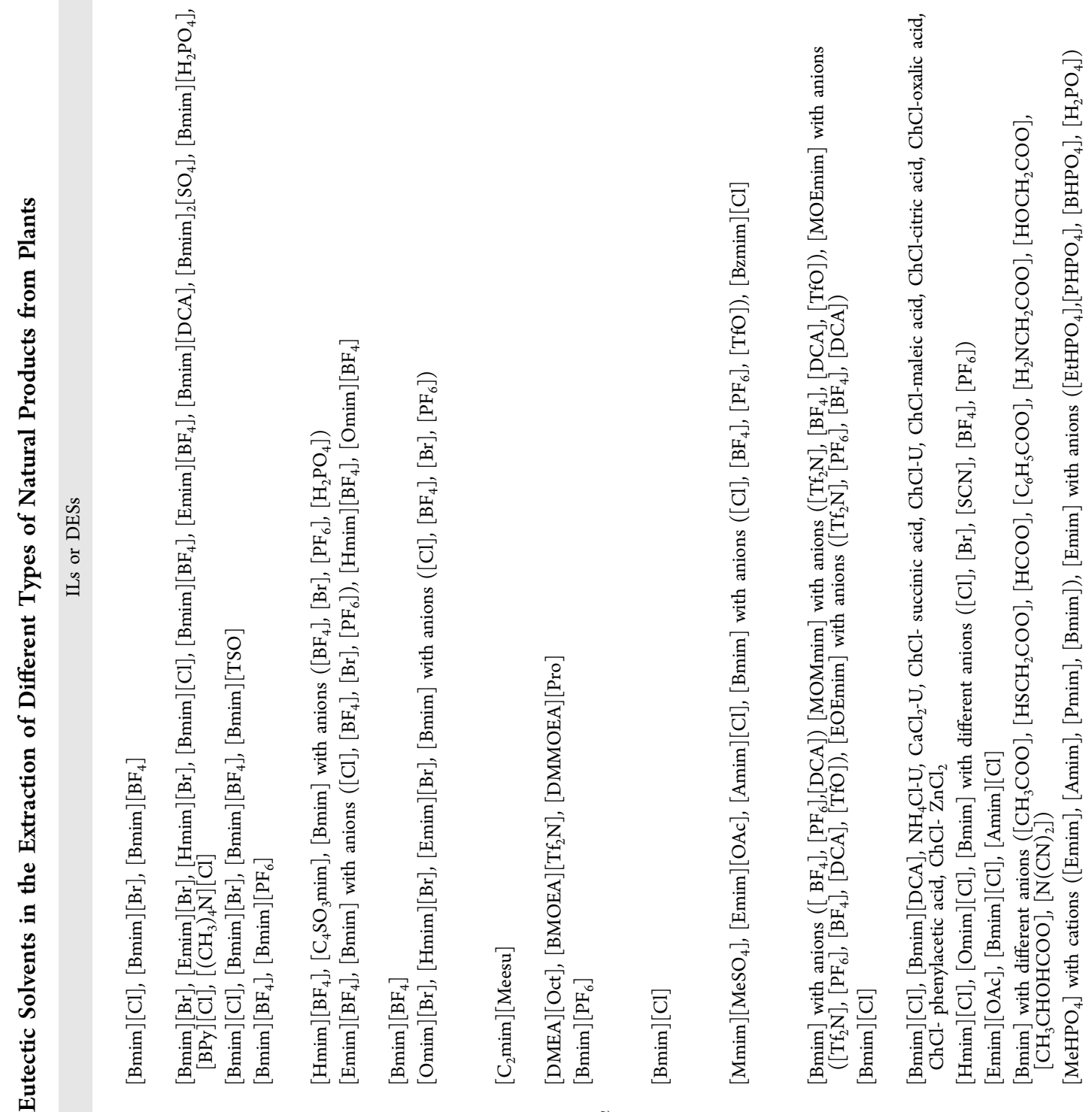

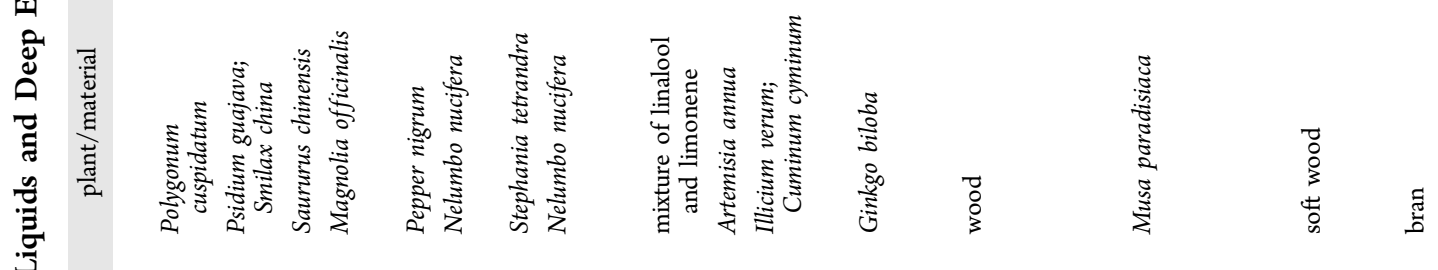

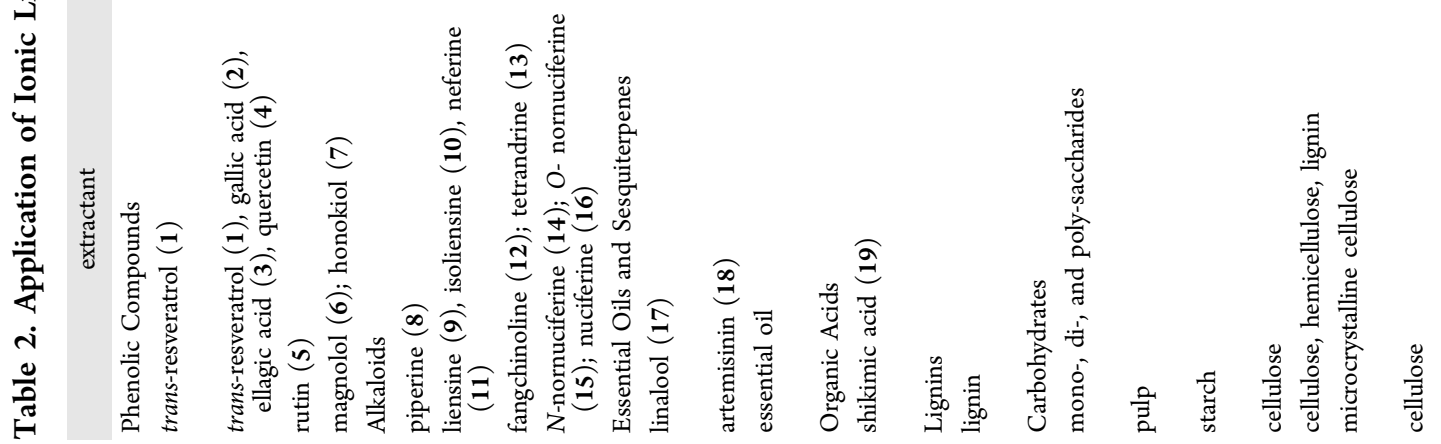




\section{Chart 1}<smiles>Oc1ccc(/C=C/c2cc(O)cc(O)c2)cc1</smiles>

1

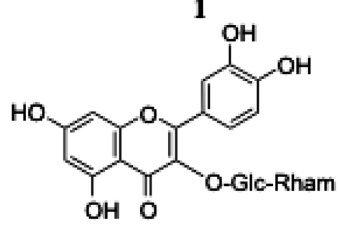<smiles>CCOc1ccc(CC2c3c(O)cc(OC)c(OC)c3Oc3cc(CN4CCN(C)CC4)ccc3C2c2ccc(OC)cc2OC)cc1</smiles><smiles>O=C(O)c1cc(O)c(O)c(O)c1</smiles>

2

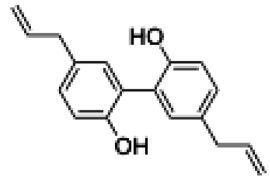<smiles>O=C1Oc2c(O)c(O)cc3c2c(=O)oc2c(O)c(O)cc1c23</smiles>

3

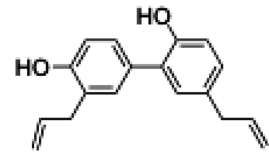

7<smiles>O=c1c(O)c(-c2ccc(O)c(O)c2)oc2cc(O)cc(O)c12</smiles><smiles>O=C(/C=C/C=C/c1ccc2c(c1)OCO2)N1CCCCC1</smiles>

8

9: $\mathrm{R}_{1}=\mathrm{H}, \mathrm{R}_{2}=\mathrm{CH}_{3}$ 10: $\mathrm{R}_{1}=\mathrm{CH}_{3}, \mathrm{R}_{2}=\mathrm{H}$ 11: $\mathrm{R}_{1}=\mathrm{R}_{2}=\mathrm{CH}_{3}$

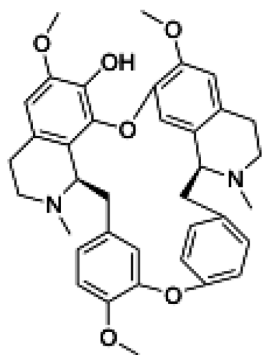

12

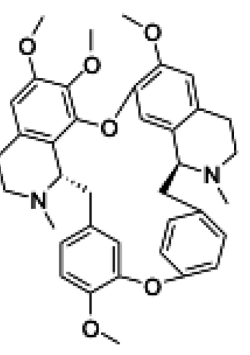

13<smiles>[R]c1cc2c3c(c1[R])-c1ccccc1CC3N([R3])CC2</smiles>

14: $\mathbf{R}_{1}=\mathbf{R}_{2}=\mathrm{OCH}_{3}$ 15: $\mathrm{R}_{1}=\mathrm{OH}, \mathrm{R}_{2}=\mathrm{OCH}_{3}, \mathrm{R}_{3}=\mathrm{CH}_{3}$ 16: $\mathbf{R}_{1}=\mathbf{R}_{2}=\mathrm{OCH}_{3}, \mathbf{R}_{3}=\mathrm{CH}_{3}$

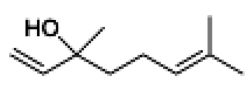

17

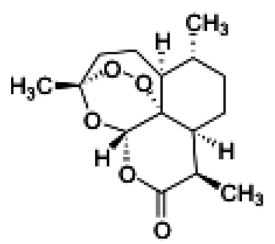

18<smiles>O=C(O)C1=C[C@H](O)[C@H](O)[C@H](O)C1</smiles>

19 absorption performance of ILs $\left([\mathrm{Bmim}]\left[\mathrm{PF}_{6}\right]\right)$ is better than water, and this reduces exposure of the essential oils and decreases the amount of oxy-compound ratio in the fraction obtained with MAE as opposed to that obtained by distillation. $^{62}$ Furthermore, ILs have advantages in terms of selectivity or/and high extraction efficiency over normal organic solvents. [Emim][Meesu], for example, demonstrated a high selectivity (extraction ratio close to 1 ) in the extraction of linalool (17) from citrus essential oil. ${ }^{63}$ [BMOEA] $\left[\mathrm{Tf}_{2} \mathrm{~N}\right]$ exhibited a high efficiency in the extraction of artemisinin (18), proving to be more efficient at a faster rate if compared to hexane extraction. ${ }^{29}$ Again, the selection of ILs for the extraction of essential oils depends on the extraction method. Some ILs with a long alkyl chain or with lower polarity anions such as $\left[\mathrm{Tf}_{2} \mathrm{~N}\right]^{29}$ were used directly in a liquid-solid extraction, while a $[\mathrm{Bmim}]\left[\mathrm{PF}_{6}\right]$ aqueous solution with a relatively higher polarity also proved to be highly efficient with ILMAE. ${ }^{62}$

Lignin. Lignin is an aromatic polymer composed of phenylpropanoids, and its extraction is anion-dependent. It is highly soluble in polar ILs with anions such as [XS], [ABS], $[\mathrm{Cl}],\left[\mathrm{MeSO}_{4}\right],[\mathrm{TfO}]$, and $[\mathrm{OAc}]$, while it is not soluble in less polar ILs with $\left[\mathrm{BF}_{4}\right]$ and $\left[\mathrm{PF}_{6}\right]$ anions. ${ }^{64,65}[\mathrm{Bmim}]\left[\mathrm{PF}_{6}\right]$ extracted the phenylpropanoids magnolol (6) and honokiol (7) very efficiently, ${ }^{58}$ but could not solubilize phenylpropanoid polymers. Lignocellulose is a major source of lignin, and a highly concentrated solution of chemically unmodified lignin has been obtained from lignocelluloses with $[\mathrm{Emim}][\mathrm{OAc}]{ }^{64}$
Carbohydrates. Carbohydrates are sparingly soluble in common organic solvents. However, ILs containing the dicyanamide anion ([DCA $]$ ) are able to dissolve glucose in high concentrations $\left(>100 \mathrm{~g} \mathrm{~L}^{-1}\right)^{66}$ and di- and trisaccharides in considerable but unspecified amounts. ${ }^{67,68}$ Sheldon proved [DCA]-based ILs to be highly effective, nonprotic solvents, capable of dissolving carbohydrates from glucose to starch and even cellulose in large amounts. ${ }^{69}$ Fort et al. ${ }^{70}$ has found that banana pulp at any stage could be completely dissolved in $[\mathrm{Bmim}][\mathrm{Cl}]$ or a $[\mathrm{Bmim}][\mathrm{Cl}] / \mathrm{DMSO}-d_{6}$ mixture, while neat DMSO- $d_{6}$ under the same conditions led only to partial dissolution of the samples. Another example was the solubililization of up to $10 \%(\mathrm{w} / \mathrm{w})$ of starch in [Bmim] [DCA] or $[\mathrm{Bmim}][\mathrm{Cl}]$ at $80{ }^{\circ} \mathrm{C}^{71}$

Cellulose is insoluble in water and most common organic liquids. Recent studies have found, however, that cellulose could be dissolved, without derivatization, in some hydrophilic ILs such as $[\mathrm{Bmim}][\mathrm{Cl}]$ and $[\mathrm{Amim}][\mathrm{Cl}] .^{24,72}$ Unfortunately, these ILs are toxic and have a high $T_{\mathrm{m}}$ and viscosity, requiring energy for the dissolution. To overcome these drawbacks, several ILs with alkylimidazolium carboxylates, such as acetate and formate salts with lower viscosity, were applied to dissolve cellulose from wood biomass in high concentrations. ${ }^{73}$ These ILs with carboxylates, however, are not particularly thermally stable. In a further stage, alkylimidazolium cations coupled with alkylphosphates, $[$ Emim $]\left[\mathrm{H}_{2} \mathrm{PO}_{4}\right]$ and $[\mathrm{Emim}]\left[\mathrm{MeHPO}_{4}\right]$, were found to be good solvents for cellulose, with a low viscosity and thermal stability. ${ }^{74}$ In general, ILs with various 
anions, such as $[\mathrm{Cl}]$, carboxylates, or alkylphosphates, provide good solubility for cellulose.

Dissolution of cellulose is anion-dependent and is based on the disruption of inter- and intrahydrogen bonding of cellulose and the formation of new hydrogen bonds between the anions of ILs and the hydroxy groups of carbohydrates. ${ }^{75}$ Highly polar ILs from $[\mathrm{Bmim}][\mathrm{DCA}],[\mathrm{Bmim}][\mathrm{Cl}]$, and $[\mathrm{Bmim}][\mathrm{OAC}]$ to $[$ Emim $]\left[\mathrm{H}_{2} \mathrm{PO}_{4}\right]$ have a good solubilizing power of different carbohydrates. Further studies have shown that the dissolution of cellulose increases with the hydrogen-bond-accepting ability (hydrogen-bonding basicity $\beta$ ) of its anions, ${ }^{76}$ and among polar ILs with similar $\beta$ values, the extraction ability of ILs for polysaccharides in a limited time is dependent on the viscosity of ILs. ${ }^{74}$ Another important factor that affects the solubility of cellulose is the temperature. Cellulose does not dissolve in ILs under ambient conditions, but when heated to $100-110{ }^{\circ} \mathrm{C}$ dissolution occurs at a slow rate in 3-methylimidazolium-based ILs containing $[\mathrm{Cl}],[\mathrm{Br}]$, or $[\mathrm{SCN}]^{24}$ Moreover, microwave heating significantly accelerates the dissolution process, increasing the solubility of cellulose in $[\mathrm{Bmim}][\mathrm{Cl}]$ up to $25 \% .{ }^{24}$ Cellulose was found to dissolve in $[\mathrm{Emim}]\left[\mathrm{H}_{2} \mathrm{PO}_{4}\right]$ at room temperature, but its solubility increased 3-fold (up to $42 \%)$ at $50{ }^{\circ} \mathrm{C}^{74}$

From the extraction studies mentioned above, it is clear that ILs are excellent solvents for all those types of compounds, showing faster or at least an equivalent rate of extraction and solubilizing ability for different kinds of target compounds when compared to classical solvents. Another aspect of extraction is the selectivity of solvents. Some studies have revealed differences between the selectivity of ILs and common organic solvents. For example, obvious differences in the components and in the content of one compound have been observed in the chromatograms of essential oil components extracted by distillation and $\operatorname{ILMAE}\left([\mathrm{Bmim}]\left[\mathrm{PF}_{6}\right]\right){ }^{62}$ Furthermore, the extracts obtained by ILs also showed high biological activities against bacteria or insects. ${ }^{77}$

Overall, when compared with the current industrial extraction methods based on volatile organic solvents, ILs are promising solvents for the extraction of active metabolites in terms of environmental, economical, and pharmaceutical aspects.

Features of ILs That Affect Their Extraction Efficiency. Considering the information provided above, in this section more general aspects of ILs as extraction solvents will be discussed. First, it is important to bear in mind that, as in all dissolution processes, the interactions between solutes and solvents are the main driving force for extraction. Hydrogen bonding and van der Waals interaction energy have been shown to effectively characterize the complex multiple interactions in the IL system. Thus the chemical structures of the components of the ILs (including the kind of anion, cation, and the alkyl chain length of the cation) have a significant influence on the extraction yield of analytes, owing to their distinct multiple interactions. ${ }^{56}$ Second, the viscosity of ILs has to be considered, as it has a great effect on the diffusion of solutes.

Type of Anion. The extraction efficiency of most compounds is anion-dependent. Solutes are strongly solvated, principally by the formation of H-bonds with the anions of the ILs. ${ }^{78}$ COSMO-RS computation simulation has revealed that the solubility of flavonoids in the same class of ILs is strongly anion-dependent. ${ }^{57}$ These experiments showed $[\mathrm{Br}],\left[\mathrm{BF}_{4}\right]$, $[\mathrm{Cl}],\left[\mathrm{H}_{2} \mathrm{PO}_{4}\right],\left[\mathrm{SO}_{4}\right],[\mathrm{DCA}]$, and $[\mathrm{OAC}]$ to be the most commonly used anions in the extraction of phenolic compounds, alkaloids, lignin, and carbohydrates, all of which are hydrogenbond donors. In the extraction of lignin, cellulose, and starch from biomass, the H-bonding between solute and solvent molecules must be strong enough to break down inter- and intramolecular $\mathrm{H}$-bonds in the biomass, and only ILs with anions with a strong $\mathrm{H}$-bond accepting ability work. ILs with anions such as $[\mathrm{Cl}],[\mathrm{OAC}]$, and $\left[\right.$ alkylHPO$\left._{4}\right]$ with a $\beta$ value of around 1 are efficient solvents, whereas ILs with $[\mathrm{Br}]$ and $\left[\mathrm{BF}_{4}\right]$ are inefficient. $^{24,74}$ The same applies to DESs formed between choline chloride and oxalic acid/citric acid, which are able to dissolve starch. ${ }^{71}$ In the liquid-liquid extraction of neutral alkaloids and phenols from water, the $\mathrm{H}$-bonding interactions between anions and solutes are the prevailing forces.

Type of Cation. The cation species also has an effect on the extraction efficiency. ILs that have cations with an electron-rich aromatic $\pi$-system have been observed to produce stronger interactions with polarizable solute molecules, such as $\pi-\pi$ and $n-\pi$ interactions. ${ }^{56,79}$ The extraction yield of phenolic compounds proved to be a little higher for $[\mathrm{BPy}][\mathrm{Cl}]$ than $[\mathrm{Bmim}][\mathrm{Cl}]$ and lowest for $\left[\left(\mathrm{CH}_{3}\right)_{4} \mathrm{~N}\right][\mathrm{Cl}]$, because the $\mathrm{N}$-butylpyridinium cation has a more aromatic character than the imidazolium-based ILs, whereas the ammonium cation does not give $\pi-\pi$ and $n-\pi$ interactions. ${ }^{31}$

Alkyl Chain of the Cation. Low symmetry in substitution and a longer alkyl chain within a certain range lead to a low $T_{\mathrm{m}}$. In the case of imidazolium cations, ILs applied to the extraction of natural products have $\left[\mathrm{C}_{n} \mathrm{mim}\right](n=2-8)$ cations, and $\mathrm{C}_{8}$ gives the lowest $T_{\mathrm{m}}{ }^{11}$ The alkyl chain length of the cation affects the extraction yield of some natural products, as its hydrophobicity increases with increasing alkyl chain length. Apart from the hydrophobicity, viscosity also increases, so that while the longer chain length benefits the extraction of some middle to less polar compounds, the increase in viscosity limits the diffusion of compounds. ILs with a cation such as [Bmim] are most often used for midpolar compounds and [Hmim] for nonpolar compounds. ${ }^{26,31,80,81}$

Viscosity. The viscosity of ILs is determined by the cation and anion species. The longer the substituted chain of the cation, the more viscous the ILs. Viscosity is one of the biggest obstacles for the application of ILs in natural product extraction. Two efficient methods have been used to decrease the viscosity: increasing the temperature through heating or microwaves ${ }^{24,25,62}$ and dilution with water or organic solvents such as ethanol. The extraction ratio of compounds can be increased by $60-90 \%$ by adjusting the concentration of ILs, ${ }^{25,26,31}$ showing that this factor is crucial since it balances not only the viscosity but also the extraction ability of the IL solutions. The optimal concentration of ILs differs according to the type of ILs, the targeted compounds, and the biomass. ${ }^{5,59}$

These observations are important to achieve an improved understanding of the ILs' solvation properties and reflect their versatility and their potential for tailoring the composition of IL for the efficient extraction of the desired natural compounds.

Combination of ILs with Other Technologies. Microwave-Assisted Extraction. ILs can efficiently absorb and transfer microwaves ${ }^{82}$ and, thus, be employed to rapidly heat solvents and cosolvents in microwave-assisted extraction (MAE). MAE is rapid and effective compared to traditional extraction techniques ${ }^{55}$ and easy and cheap compared with other modern extraction techniques. ${ }^{83}$ Recently, IL-based microwave-assisted extraction methods have been evaluated for the extraction of some phenolic compounds, ${ }^{25,31,55}$ alkaloids, ${ }^{59,61}$ and essential oils ${ }^{62}$ from medicinal plants. Compared to conventional heat-reflux 
extraction (HRE), MAE has the advantage of being remarkably more efficient (20-50\% higher) with lower extraction times, reduced from $2 \mathrm{~h}$ to $90 \mathrm{~s}$.

The influential parameters of the ILMAE procedure include the sample size, liquid/solid ratio, extraction time, and temperature. The extraction rate of phenolic alkaloids with $[\mathrm{Hmim}]\left[\mathrm{BF}_{4}\right]$ increased when the liquid/solid ratio was raised from $5: 1$ to $10: 1$ and decreased dramatically when the ratio further increased to 20:1. An extraction time of around 8-12 min is sufficient to obtain high extraction yields of phenolic compounds from 0.2 to $0.5 \mathrm{~g}$ of plant material with $20-35 \mathrm{~mL}$ of a $1.5-2.0 \mathrm{~mol} / \mathrm{L}[\mathrm{Bmim}][\mathrm{Br}]$ aqueous solution. ${ }^{55}$ Another aspect to be considered is thermal stability. Phenolic compounds have been found to be stable up to $100{ }^{\circ} \mathrm{C}$ during $\mathrm{MAE}^{84}$ but with ILs as the solvent the stability temperature decreases to $60-80{ }^{\circ} \mathrm{C}$; compounds with a larger number of hydroxy group substituents are more readily degraded under the extraction conditions. ${ }^{31}$

ILMAE is highly efficient as an extraction method due to its unique mechanism. In ILMAE extraction, the direct interaction of the microwaves with the IL solution and free molecular water present in the cells results in the rupture of the cells and release of intracellular products into the solvent. The surface of the plant material was observed to be greatly damaged and the structure of the cell walls ruptured after ILMAE. ${ }^{31,55}$ Moreover, ILs improve the transfer of energy from the microwaves to the sample, increasing the speed of energy transfer and thus extraction efficiency. ${ }^{83}$

Ultrasound-Assisted Extraction. IL-based ultrasound-assisted extraction methods have been developed for the effective extraction of alkaloids ${ }^{26,60}$ and phenolic compounds ${ }^{58}$ from plant material. The extraction time is one of the most important factors, and optimal extraction efficiency can be achieved in 30-40 min. The extraction efficiency of the optimized ILUAE approach increases by ca. $30-45 \%$ when compared with UAE but with a conventional solvent (ethanol). ${ }^{26}$

\section{ANALYSIS METHODS FOR EXTRACTION BY IONIC LIQUIDS}

High-Performance Liquid Chromatography. It is quite often necessary to concentrate plant extracts for their analysis. While this is relatively simple with volatile conventional solvents, this is impossible with IL extracts. In general, the sample preparation of an IL extract for HPLC analysis includes dilution with water or ethanol to decrease viscosity. ${ }^{25,85} \mathrm{~A}$ reversed-phase HPLC method using a $\mathrm{C}_{18}$ column and acetonitrile and $0.6 \%$ acetic acid aqueous solution as the mobile phase has been used to analyze the phenolic compounds in IL extracts of medicinal plants, with no interference from the ILs being observed. ${ }^{25,31,59}$ The method showed good reproducibility, precision, and accuracy, with no degradation of the target compounds. The presence of ILs did not affect the usual chromatographic parameters such as peak resolution, peak shape, elution order, and retention times in the separation of three phenolic alkaloids. ${ }^{59}$ Cao et al. ${ }^{26}$ came to the same conclusion when analyzing a nondiluted IL piperine (8) extract with UPLC on a $\mathrm{C}_{18}$ column. In another case, HPLC-DADELSDA with a $\mathrm{C}_{18}$ column has been used to determine the esterification of flavonoids in ILs. ${ }^{86}$ All these studies show that ILs can be used as extraction solvents for the analysis of natural products from a biological matrix, without the need to eliminate the ILs previously, opening interesting novel opportunities for the use of these solvents for sample preparation for the quantitative analysis of natural products.

Nuclear Magnetic Resonance Spectroscopy. ${ }^{13} \mathrm{C}$ NMR spectroscopy has been applied to analyze carbohydrates extracted with ILs to detect their content, conformation, and interactions. The direct measurement of IL banana pulp extracts gave well-resolved signals in the ${ }^{13} \mathrm{C}$ NMR spectra corresponding to different sugars in the anomeric carbon region that could be used for quantitative analysis. ${ }^{70}$ Solid-state ${ }^{13} \mathrm{C}$ NMR spectroscopy was used to monitor the extraction of lignin from lignocellulose material dissolved in ILs. ${ }^{65}$ It is known that ${ }^{13} \mathrm{C}$ NMR spectroscopy is a very useful tool in the study of the conformational preferences of repetitive polysaccharides, ${ }^{87}$ but a drawback for its application to IL extracts is their high viscosity since this reduces molecular tumbling, resulting in low resolution and sensitivity. However, the spectrum recorded at $90{ }^{\circ} \mathrm{C}$ exhibited baseline resolution for most signals. ${ }^{88} \mathrm{NMR}$ relaxation measurements of the $\mathrm{ILs}{ }^{13} \mathrm{C}$ and ${ }^{35 / 37} \mathrm{Cl}$ nuclei provided a better understanding of the mechanism of solvatation of cellulose, the destruction of $\beta$ - $(1 \rightarrow 4)$-linked glucose oligomers, ${ }^{88}$ and the formation of $\mathrm{H}$-bonds between the carbohydrate hydroxy group protons and the IL chloride ions. $^{75,76}$ The HOESY spectrum of choline fluoride and urea showed intense cross-correlations between the fluoride ion and the primary amine protons of urea, revealing the existence of hydrogen bonding in the liquid. ${ }^{8}$ Thus, IL extracts can be analyzed by NMR spectroscopy, but the various signals of the protons in the IL constituent will, in fact, overlap with sample signals in certain spectral regions.

Microscopy. Scanning electron microscopy (SEM) allows the observation and characterization of heterogeneous organic and inorganic materials at a nano- to micrometer scale. The popularity of SEM stems from its capacity to obtain 3D-like images of the surface of a very wide range of materials. XL-30 SEM spectroscopy has been applied to identify the microstructure of plant material after MAE using a $[\mathrm{Bmim}][\mathrm{Br}]$ solution as a solvent, revealing the structure of the cell walls to be ruptured and the microstructure of leaves and tubers greatly destroyed, as shown by SEM images (Figure 1). ${ }^{31}$

\section{SEPARATION OF NATURAL PRODUCTS FROM ILS}

Supercritical Carbon Dioxide. The low volatility of ILs that on one hand makes them "green" creates challenges for product separation and recovery. For volatile products, a backdistillation may be used to recover the product from ILs. In the case of a hydrophilic product in a hydrophobic IL, water may be used to remove the product from the ILs, ${ }^{89}$ but the biggest problem is to recover poorly volatile or thermally labile products from ILs.

Experiments using another type of "green" solvent, supercritical carbon dioxide $\left(\mathrm{SC}-\mathrm{CO}_{2}\right)$, for product recovery from IL solution have been reported. The volatile $\mathrm{SC}-\mathrm{CO}_{2}$ is insoluble in the nonvolatile and polar ILs, and they form two-phase systems. The principle of product recovery with these biphasic systems is based on the solubility of the compounds in $\mathrm{CO}_{2}$. During the process, high volatility and low polarity will favor the solubility of a solute in $\mathrm{CO}_{2}$. Naphthalene has been extracted from $[\mathrm{Bmim}]\left[\mathrm{PF}_{6}\right]$ using $\mathrm{SC}-\mathrm{CO}_{2}$ with recoveries of up to 94-96\%, a near-quantitative recovery without detectable $[\mathrm{Bmim}]\left[\mathrm{PF}_{6}\right]$ in the extract. ${ }^{90}$ Several aromatic and aliphatic compounds have also been quantitatively recovered from this $\mathrm{IL}$ with $\mathrm{SC}-\mathrm{CO}_{2}$ without any $\mathrm{IL}$ contamination in the recovered product. ${ }^{91}$ Diverse compounds such as $\mathrm{N}$-acetyl-(S)-phenylalanine methyl 

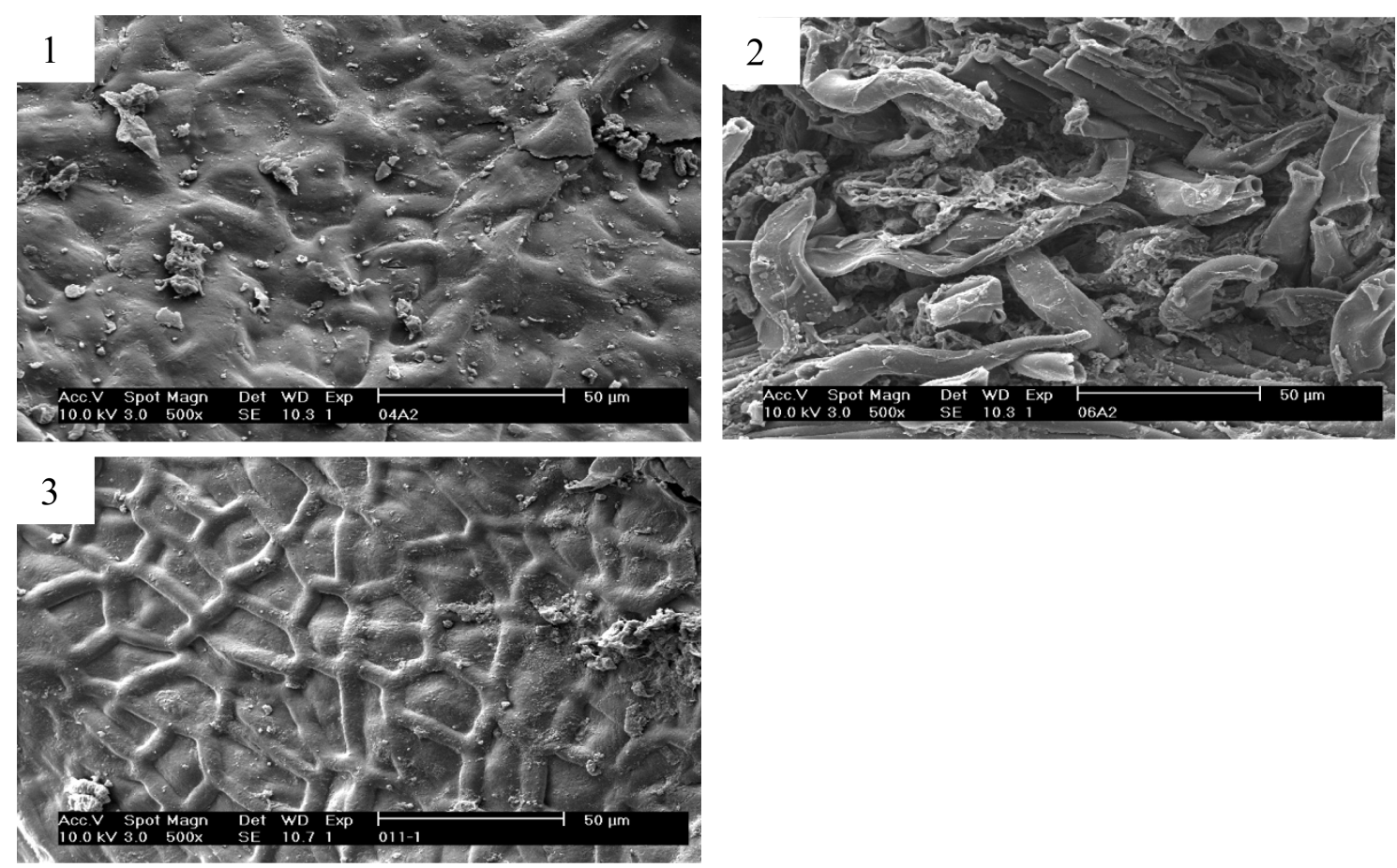

Figure 1. Scanning electron micrographs of Psidium guajava leaves: (1) untreated P. guajava leaves; (2) after MAE for 10 min in [Bmim][Br]; and (3) after heating extraction for $4 \mathrm{~h}$. Image magnification is $500 \times$ for A, B, and C. Reprinted with permission from ref 31.

ester and epoxides of olefins have been extracted from ILs with $\mathrm{SC}-\mathrm{CO}_{2}$ by optimizing pressure, temperature, and the type of $\mathrm{IL}$, especially from enzyme-catalyzed reactions. ${ }^{28,92}$ The product of asymmetric hydrogenation of tiglic acid in $[\mathrm{Bmim}]\left[\mathrm{PF}_{6}\right]$, 2-methylbutanoic acid, has been extracted with $\mathrm{SC}-\mathrm{CO}_{2}$. Moreover, recycling of the catalyst in $[\mathrm{Bmim}]\left[\mathrm{PF}_{6}\right]$ was achieved without significant losses of neither enantioselectivity nor conversion. ${ }^{93}$

The removal of a product from ILs by extraction with $\mathrm{CO}_{2}$, however, works only for products that have a sufficiently high solubility in $\mathrm{CO}_{2}$. For compounds that are insoluble in $\mathrm{CO}_{2}$, crystallization from ILs with $\mathrm{CO}_{2}$ as an antisolvent has been explored. The addition of $\mathrm{CO}_{2}$ lowers the solubility of the product in the ILs, thereby creating supersaturation. ${ }^{28}$ With this method, removal of even solid, inorganic salts from [Hmim]$\left[\mathrm{Tf}_{2} \mathrm{~N}\right]$ has been achieved with $\mathrm{CO}_{2}$ at $25{ }^{\circ} \mathrm{C}$. ${ }^{94}$ Strong hydrogen-bonding interactions between the ILs and the solutes make it more difficult to induce a separation. Further studies have revealed that $\mathrm{CO}_{2}$ acts primarily by disrupting the nonspecific interactions in the IL/organic mixtures ${ }^{95}$ and that the ability of $\mathrm{CO}_{2}$ to act as an antisolvent is highly dependent on the solubility of $\mathrm{CO}_{2}$ in the IL/organic mixtures. Kroon et al. ${ }^{96}$ found that methyl- $(Z)-\alpha$-acetamido cinnamate could be recovered from $[\mathrm{Bmim}]\left[\mathrm{BF}_{4}\right]$ by either shifting to a higher $\mathrm{CO}_{2}$ concentration at a constant temperature (antisolvent crystallization) or changing to lower temperatures at constant $\mathrm{CO}_{2}$ concentration, showing the importance of exploring the effects of pressure, temperature, and $\mathrm{CO}_{2}$ concentration in each case.

Antisolvents. In general, adding antisolvent with agitation may result in the separation of solutes from ILs. In some examples water, ethanol, or acetone have been used to isolate cellulose from $[\mathrm{Bmim}][\mathrm{Cl}]$ or $[\mathrm{Bmim}]\left[\mathrm{CH}_{3} \mathrm{COO}\right],^{24,76}$ water, methanol, or acetone to extract wool keratin from [Bmim]$[\mathrm{Cl}],{ }^{97}$ or mixtures of acetone/water $(1: 1)$ to isolate cellulose and lignin from $[$ Emim $][\mathrm{OAC}] .^{73}$ Lignin has also been separated by precipitation from [Emim] $[\mathrm{XS}]$ by acidification to $\mathrm{pH} 2$ at room temperature followed by the recovery of the IL by neutralization, removal of water at reduced pressures, and drying at $70{ }^{\circ} \mathrm{C}$ under high-vacuum conditions. ${ }^{65}$

Recrystallization. Recrystallization by cooling or adding antisolvents can be used to separate solution and target molecules. The addition of 1-butanol to $\mathrm{Gly}-\mathrm{ChCl}$ with extra glycine and then subcooling to $-20{ }^{\circ} \mathrm{C}$ allowed the separation of choline chloride. ${ }^{32}$ Water has been used as an antisolvent (3:1 v/v $\mathrm{H}_{2} \mathrm{O}$ to ILs) to partition and then recrystallize artemisinin from ILs with a yield of $82 \%$ of the total extracted artemisinin and a $95 \%$ concentration of anhydrous artemisinin. ${ }^{29}$

Back Extraction. Organic acids, nitrogen-containing compounds, phenolic compounds, and amino acids have been removed from ILs using back extraction with aqueous solutions with necessary $\mathrm{pH}$ adjustment, and ILs can also be recovered quantitatively after neutralization and evaporation of the solvent. For example, nitrogen-containing compounds were recovered from $[\mathrm{Bmim}][\mathrm{Cl}]$ by back extraction using water or methanol. ${ }^{98}$ A 94-98\% recovery of ferulic acid from [Bmim]$\left[\mathrm{PF}_{6}\right]$ was achieved with a $0.02 \mathrm{M} \mathrm{NaOH}$ aqueous solution. ${ }^{17}$ In another case, $99 \%$ of phenols present were removed from $[\mathrm{Bmim}]\left[\mathrm{PF}_{6}\right]$ after back extraction with a $0.1 \mathrm{~mol} \mathrm{~L}^{-1} \mathrm{NaOH}$ aqueous solution. ${ }^{20}$ Amino acids were recovered from AAILs by adjusting the $\mathrm{pH}$ of the solution to 7.0 with $\mathrm{HCl}$, thus neutralizing the amino group. ${ }^{19}$

Chromatographic Techniques. In addition, some column chromatographic techniques have been developed for the separation and purification of compounds from IL extracts. An anion-exchange resin has been used successfully in the isolation and purification of shikimic acid (19) from $[\mathrm{Bmim}][\mathrm{Cl}]$ extract with a $87 \%$ yield. ${ }^{30}$ High-speed countercurrent chromatography has been used in the separation and purification of three isoflavones from a $\left[\mathrm{C}_{8} \mathrm{~min}\right][\mathrm{Br}]$ extract with purity above $95 \%{ }^{99}$ Nonporous membranes with a selective layer of hydrophilic or 
hydrophobic polymers have been applied for the quantitative and selective recovery of solutes with different physicochemical properties from $[\mathrm{Bmim}]\left[\mathrm{PF}_{6}\right]$. ${ }^{100}$

Thus, although ILs cannot be removed from extracts by evaporation, diverse methods have been employed successfully to isolate compounds from ILs, as described above. The solvents used in these processes are also green solvents such as $\mathrm{SC}-\mathrm{CO}_{2}$, water, or ethanol, ensuring the green extraction and isolation of natural products from live material with ILs. Furthermore, the ILs can also be reused several times, thereby decreasing the cost of the whole process.

\section{CONCLUSION AND PERSPECTIVES}

ILs are promising solvents for natural products research basically due to their high extraction efficiency of a wide range of metabolites, their selectivity for certain compounds, and their low environmental impact. First, their ability to dissolve completely biomass facilitates the release of the metabolites in cells, which increases significantly the extraction yield and extraction efficiency of a broad range of metabolites. $^{27,30}$ The high dissolving ability of ILs implies their prospect in extracting all metabolites in a single extraction. Second, some ILs and DESs have already been used in the selective extraction of certain compounds. ${ }^{19,32}$ Third, their negligible vapor pressure at ambient conditions allows the direct distillation and separation of volatile compounds at mild conditions, which is energy-saving, without contamination, and also good for fragile components. All these results show their great potential for further applications in natural productsrelated areas such as food additives and pharmaceuticals or cosmetics.

Two properties of ILs or DESs that lead to limitations in natural products research are their high viscosity and negligible volatility. Water dilution and several recovery methods have been applied successfully to resolve these problems. Although these steps are involved in sample preparation, most of the solvents used are natural solvents such as water or supercritical carbon dioxide. Furthermore, the high water solubility of ILs mostly used and DESs ensure the separation or isolation of solutes from these solvents only with water elution in chromatography. The insolubility of ILs in $\mathrm{CO}_{2}$ ensures the compounds recovered without contamination. In addition, the recovered ILs can be reused several times.

In the natural products field, there are a number of reports on the efficient extraction of certain types of materials using aqueous IL solutions combined with supercritical $\mathrm{CO}_{2}$. Most of these studies have been established for model compounds as a means of exploring the recovery mechanism, but applications to a wider range of compounds still need to be developed. This method might also be a good choice for the extraction of thermally unstable compounds. In addition, it may also be useful to develop a liquid/solid separation using different column materials to separate target solutes and ILs. Thus, further work has to be done on the recovery of compounds from these extracts. Another aspect to be improved is the high viscosity of most of these solvents.

Finally, after considering all the information provided above, our group has postulated recently that ILs and DESs also occur in nature. ${ }^{10}$ Many metabolites of organisms change their state from solid to liquid when they are mixed, representing natural deep eutectic solvents. The existence of NADES would explain, for example, the biosynthesis of the water-insoluble macromolecules cellulose, lignin, and starch, the biosynthesis of small water-insoluble molecules, the drought and cold resistance of all kinds of organisms, and the germination of an almost dry seed. ${ }^{10}$ These liquids are mostly made of primary metabolites as well as water and show great promise in applications in healthrelated areas due to their low viscosity and, especially, their sustainable and biocompatible properties. ${ }^{101}$

\section{ASSOCIATED CONTENT}

Supporting Information

This material is available free of charge via the Internet at http://pubs.acs.org.

\section{AUTHOR INFORMATION}

\section{Corresponding Author}

*E-mail: y.choi@chem.leidenuniv.nl. Tel: +31 (071) 527-4510. Fax: +31 (071) 527-4511.

Notes

The authors declare no competing financial interest.

\section{ACKNOWLEDGMENTS}

This work was supported by an NWO ECHO grant (Project No. 711.012.010) and a Horizon Valorisation grant (Project No. 93515516). Y.D. greatly appreciates the support from the Ph.D. program of the China Scholarship Council. The authors thank Dr. E. G. Wilson at Leiden University for language revision.

\section{REFERENCES}

(1) Welton, T. Chem. Rev. 1999, 99, 2071-2084.

(2) Abbott, A. P.; Boothby, D.; Capper, G.; Davies, D. L.; Rasheed, R K. J. Am. Chem. Soc. 2004, 126, 9142-9147.

(3) Swatloski, R. P.; Holbrey, J. D.; Rogers, R. D. Green Chem. 2003, $5,361-363$.

(4) Garcia-Lorenzo, A.; Tojo, E.; Tojo, J.; Teijeira, M.; RodriguezBerrocal, F. J.; Gonzalez, M. P.; Martinez-Zorzano, V. S. Green Chem. 2008, 10, 508-516.

(5) Tao, G. H.; He, L.; Liu, W. S.; Xu, L.; Xiong, W.; Wang, T.; Kou, Y. Green Chem. 2006, 8, 639-646.

(6) Fukaya, Y.; Iizuka, Y.; Sekikawa, K.; Ohno, H. Green Chem. 2007, 9, 1155-1157.

(7) Hu, S. Q.; Jiang, T.; Zhang, Z. F.; Zhu, A. L.; Han, B. X.; Song, J. L.; Xie, Y.; Li, W. J. Tetrahedron Lett. 2007, 48, 5613-5617.

(8) Abbott, A. P.; Capper, G.; Davies, D. L.; Rasheed, R. K.; Tambyrajah, V. Chem. Commun. 2003, 70-71.

(9) Imperato, G.; Eibler, E.; Niedermaier, J.; Konig, B. Chem. Commun. 2005, 1170-1172.

(10) Choi, Y. H.; van Spronsen, J.; Dai, Y.; Verberne, M.; Hollmann, F.; Arends, I. W. C. E.; Witkamp, G. J.; Verpoorte, R. Plant Physiol. 2011, 156, 1701-1705.

(11) Zhang, S.; Lu, X.; Zhang, Y.; Zhou, Q.; Sun, J.; Han, L.; Yue, G.; Liu, X.; Cheng, W.; Li, S. In Molecular Thermodynamics of Complex Systems; Liu, X.; Hu, Y., Eds.; Springer: Berlin, 2009; Vol. 131, pp 143-191.

(12) Visser, A. E.; Swatloski, R. P.; Reichert, W. M.; Mayton, R.; Sheff, S.; Wierzbicki, A.; Davis, J. J. H.; Rogers, R. D. Chem. Commun. 2001, 135-136.

(13) Tang, B.; Bi, W.; Tian, M.; Row, K. H. J. Chromatogr. B 2012, 904, 1-21.

(14) Berthod, A.; Ruiz-Angel, M. J.; Carda-Broch, S. J. Chromatogr. A 2008, 1184, 6-18.

(15) Herrera-Herrera, A. V.; Hernandez-Borges, J.; RodriguezDelgado, M. A. J. Chromatogr. A 2009, 1216, 7281-7287.

(16) Tian, M.; Yan, H.; Row, K. H. Anal. Lett. 2010, 43, 110-118.

(17) Yu, Y. Y.; Zhang, W.; Cao, S. W. Chin. J. Anal. Chem. 2007, 35, $1726-1730$.

(18) Absalan, G.; Akhond, M.; Sheikhian, L. Talanta 2008, 77, 407. 
(19) Tang, F.; Zhang, Q.; Ren, D.; Nie, Z.; Liu, Q.; Yao, S. J. Chromatogr. A 2010, 1217, 4669-4674.

(20) Fan, J.; Fan, Y.; Pei, Y.; Wu, K.; Wang, J.; Fan, M. Sep. Purif. Technol. 2008, 61, 324-331.

(21) Cláudio, A. F. M.; Freire, M. G.; Freire, C. S. R.; Silvestre, A. J. D.; Coutinho, J. A. P. Sep. Purif. Technol. 2010, 75, 39-47.

(22) Holbrey, J. D.; Lopez-Martin, I.; Rothenberg, G.; Seddon, K. R.; Silvero, G.; Zheng, X. Green Chem. 2008, 10, 87-92.

(23) Freire, M. G.; Neves, C. M. S. S.; Marrucho, I. M.; Canongia Lopes, J. N.; Rebelo, L. P. N.; Coutinho, J. A. P. Green Chem. 2010, 12, $1715-1718$.

(24) Swatloski, R. P.; Spear, S. K.; Holbrey, J. D.; Rogers, R. D. J. Am. Chem. Soc. 2002, 124, 4974-4975.

(25) Du, F. Y.; Xiao, X. H.; Li, G. K. J. Chromatogr. A 2007, 1140, $56-62$.

(26) Cao, X.; Ye, X.; Lu, Y.; Yu, Y.; Mo, W. Anal. Chim. Acta 2009, 640, 47-51.

(27) Bica, K.; Gaertner, P.; Rogers, R. D. Green Chem. 2011, 13, 1997-1999.

(28) Kroon, M. C.; van Spronsen, J.; Peters, C. J.; Sheldon, R. A.; Witkamp, G. J. Green Chem. 2006, 8, 246-249.

(29) Lapkin, A. A.; Plucinski, P. K.; Cutler, M. J. Nat. Prod. 2006, 69, $1653-1664$.

(30) Usuki, T.; Yasuda, N.; Yoshizawa-Fujita, M.; Rikukawa, M. Chem. Commun. 2011, 47, 10560-10562.

(31) Du, F. Y.; Xiao, X. H.; Luo, X. J.; Li, G. K. Talanta 2009, 78, 1177.

(32) Hayyan, M.; Mjalli, F. S.; Hashim, M. A.; AlNashef, I. M. Fuel Process. Technol. 2010, 91, 116-120.

(33) Ma, C. H.; Liu, T. T.; Yang, L.; Zu, Y. G.; Chen, X. Q.; Zhang, L.; Zhang, Y.; Zhao, C. J. J. Chromatogr. A 2011, 1218, 8573-8580.

(34) Anastas, P.; Eghbali, N. Chem. Soc. Rev. 2010, 39, 301-312.

(35) Tao, G. H.; He, L.; Sun, N.; Kou, Y. Chem. Commun. 2005, 3562-3564. Bao, W.; Wang, Z.; Li, Y. J. Org. Chem. 2002, 68, 591593.

(36) Imperato, G.; Konig, B.; Chiappe, C. Eur. J. Org. Chem. 2007, 1049-1058.

(37) Handy, S. T.; Okello, M.; Dickenson, G. Org. Lett. 2003, 5, $2513-2515$.

(38) Carter, E. B.; Culver, S. L.; Fox, P. A.; Goode, R. D.; Ntai, I.; Tickell, M. D.; Traylor, R. K.; Hoffman, N. W.; Davis, J. H. Chem. Commun. 2004, 630-631.

(39) Nockemann, P.; Thijs, B.; Driesen, K.; Janssen, C. R.; Van Hecke, K.; Van Meervelt, L.; Kossmann, S.; Kirchner, B.; Binnemans, K. J. Phys. Chem. B 2007, 111, 5254-5263.

(40) Kagimoto, J.; Fukumoto, K.; Ohno, H. Chem. Commun. 2006, 2254-2256.

(41) Jiang, Y. Y.; Wang, G. N.; Zhou, Z.; Wu, Y. T.; Geng, J.; Zhang, Z. B. Chem. Commun. 2008, 505-507.

(42) Moriel, P.; Garcia-Suarez, E. J.; Martinez, M.; Garcia, A. B.; Montes-Moran, M. A. Tetrahedron Lett. 2010, 51, 4877-4881.

(43) Wasserscheid, P.; Bosmann, A.; Bolm, C. Chem. Commun. 2002, 200-201.

(44) Ohno, H.; Fukumoto, K. Acc. Chem. Res. 2007, 40, 1122-1129.

(45) Chiappe, C.; Pieraccini, D. J. Phys. Org. Chem. 2005, 18, 275297.

(46) Gore, S.; Baskaran, S.; Koenig, B. Green Chem. 2011, 13, 10091013.

(47) Ilgen, F.; Konig, B. Green Chem. 2009, 11, 848-854.

(48) Ilgen, F.; Ott, D.; Kralisch, D.; Reil, C.; Palmberger, A.; Konig,

B. Green Chem. 2009, 11, 1948-1954.

(49) Jhong, H. R.; Wong, D. S. H.; Wan, C. C.; Wang, Y. Y.; Wei, T. C. Electrochem. Commun. 2009, 11, 209-211.

(50) Abbott, A. P.; Cullis, P. M.; Gibson, M. J.; Harris, R. C.; Raven, E. Green Chem. 2007, 9, 868-872.

(51) Gorke, J. T.; Srienc, F.; Kazlauskas, R. J. Chem. Commun. 2008, $1235-1237$.

(52) Gutiérrez, M. a. C.; Ferrer, M. a. L.; Mateo, C. R.; del Monte, F. Langmuir 2009, 25, 5509-5515.
(53) Gutiérrez, M. a. C.; Rubio, F.; del Monte, F. Chem. Mater. 2010, 22, 2711-2719.

(54) Abbott, A. P.; Harris, R. C.; Ryder, K. S. J. Phys. Chem. B 2007, 111, 4910-4913.

(55) Zeng, H.; Wang, Y.; Kong, J.; Nie, C.; Yuan, Y. Talanta 2010, $83,582-590$.

(56) Anderson, J. L.; Ding, J.; Welton, T.; Armstrong, D. W. J. Am. Chem. Soc. 2002, 124, 14247-14254.

(57) Guo, Z.; Lue, B. M.; Thomasen, K.; Meyer, A. S.; Xu, X. Green Chem. 2007, 9, 1362-1373.

(58) Zhang, L.; Wang, X. J. Sep. Sci. 2010, 33, 2035-2038.

(59) Lu, Y.; Ma, W.; Hu, R.; Dai, X.; Pan, Y. J. Chromatogr. A 2008, $1208,42-46$.

(60) Zhang, L. J.; Geng, Y. L.; Duan, W. J.; Wang, D. J.; Fu, M. R.; Wang, X. J. Sep. Sci. 2009, 32, 3550-3554.

(61) Ma, W.; Lu, Y.; Hu, R.; Chen, J.; Zhang, Z.; Pan, Y. Talanta 2010, 80, 1292-1297.

(62) Zhai, Y.; Sun, S.; Wang, Z.; Cheng, J.; Sun, Y.; Wang, L.; Zhang, Y.; Zhang, H.; Yu, A. J. Sep. Sci. 2009, 32, 3544-3549.

(63) Francisco, M.; Lago, S.; Soto, A.; Arce, A. Fluid Phase Equilib. 2010, 296, 149-153.

(64) Lee, S. H.; Doherty, T. V.; Linhardt, R. J.; Dordick, J. S. Biotechnol. Bioeng. 2009, 102, 1368-1376.

(65) Tan, S. S. Y.; MacFarlane, D. R.; Upfal, J.; Edye, L. A.; Doherty, W. O. S.; Patti, A. F.; Pringle, J. M.; Scott, J. L. Green Chem. 2009, 11, 339-345.

(66) MacFarlane, D. R.; Golding, J.; Forsyth, S.; Forsyth, M.; Deacon, G. B. Chem. Commun. 2001, 1430-1431.

(67) Forsyth, S. A.; MacFarlane, D. R.; Thomson, R. J.; von Itzstein, M. Chem. Commun. 2002, 714-715.

(68) Forsyth, S. A.; MacFarlane, D. R. J. Mater. Chem. 2003, 13, 2451-2456.

(69) Liu, Q.; Janssen, M. H. A.; Rantwijk, F. V.; Sheldon, R. A. Green Chem. 2005, 7, 39-42.

(70) Fort, D. A.; Swatloski, R. P.; Moyna, P.; Rogers, R. D.; Moyna, G. Chem. Commun. 2006, 714-716.

(71) Biswas, A.; Shogren, R. L.; Stevenson, D. G.; Willett, J. L.; Bhowmik, P. K. Carbohydr. Polym. 2006, 66, 546-550.

(72) Zhu, S.; Wu, Y.; Chen, Q.; Yu, Z.; Wang, C.; Jin, S.; Ding, Y.; Wu, G. Green Chem. 2006, 8, 325-327.

(73) Sun, N.; Rahman, M.; Qin, Y.; Maxim, M. L.; Rodriguez, H.; Rogers, R. D. Green Chem. 2009, 11, 646-655.

(74) Abe, M.; Fukaya, Y.; Ohno, H. Green Chem. 2010, 12, 12741280.

(75) Remsing, R. C.; Swatloski, R. P.; Rogers, R. D.; Moyna, G. Chem. Commun. 2006, 1271-1273.

(76) Xu, A.; Wang, J.; Wang, H. Green Chem. 2010, 12, 268-275.

(77) Cieniecka-Rosłonkiewicz, A.; Sas, A.; Przybysz, E.; Morytz, B.; Syguda, A.; Pernak, J. Chem. Biodiversity 2007, 4, 2218-2224.

(78) Hanke, C. G.; Atamas, N. A.; Lynden-Bell, R. M. Green Chem. 2002, 4, 107-111.

(79) Crowhurst, L.; Mawdsley, P. R.; Perez-Arlandis, J. M.; Salter, P. A.; Welton, T. Phys. Chem. Chem. Phys. 2003, 5, 2790-2794.

(80) Fan, Y.; Chen, M.; Shentu, C.; El-Sepai, F.; Wang, K.; Zhu, Y.; Ye, M. Anal. Chim. Acta 2009, 650, 65-69.

(81) Li, M.; Pittman, C. U., Jr.; Li, T. Talanta 2009, 78, 1364-1370.

(82) Hoffmann, J.; Nuchter, M.; Ondruschka, B.; Wasserscheid, P. Green Chem. 2003, 5, 296-299.

(83) Eskilsson, S. C.; Björklund, E. J. Chromatogr. A 2000, 902, 227250.

(84) Liazid, A.; Palma, M.; Brigui, J.; Barroso, C. G. J. Chromatogr. A 2007, 1140, 29-34.

(85) Fu, X.; Dai, S.; Zhang, Y. Chin. J. Anal. Chem. 2006, 34, 598602.

(86) Lue, B.-M.; Guo, Z.; Xu, X. J. Chromatogr. A 2008, 1198-1199, 107-114.

(87) Swalina, C. W.; Zauhar, R. J.; DeGrazia, M. J.; Moyna, G. J. Biomol. NMR 2001, 21, 49-61. 
(88) Moulthrop, J. S.; Swatloski, R. P.; Moyna, G.; Rogers, R. D. Chem. Commun. 2005, 1557-1559.

(89) Huddleston, J. G.; Rogers, R. D. Chem. Commun. 1998, 17651766.

(90) Blanchard, L. A.; Hancu, D.; Beckman, E. J.; Brennecke, J. F. Nature 1999, 399, 28-29.

(91) Blanchard, L. A.; Brennecke, J. F. Ind. Eng. Chem. Res. 2001, 40, 287-292.

(92) Bortolini, O.; Campestrini, S.; Conte, V.; Fantin, G.; Fogagnolo, M.; Maietti, S. Eur. J. Org. Chem. 2003, 2003, 4804-4809.

(93) Brown, R. A.; Pollet, P.; McKoon, E.; Eckert, C. A.; Liotta, C. L.; Jessop, P. G. J. Am. Chem. Soc. 2001, 123, 1254-1255.

(94) Saurer, E. M.; Aki, S. N. V. K.; Brennecke, J. F. Green Chem. 2006, 8, 141-143.

(95) Mellein, B. R.; Brennecke, J. F. J. Phys. Chem. B 2007, 111, 4837-4843.

(96) Kroon, M. C.; Toussaint, V. A.; Shariati, A.; Florusse, L. J.; Spronsen, J. v.; Witkamp, G. J.; Peters, C. J. Green Chem. 2008, 10, 333-336.

(97) Xie, H.; Li, S.; Zhang, S. Green Chem. 2005, 7, 606-608.

(98) Xie, L. L.; Favre-Reguillon, A.; Pellet-Rostaing, S.; Wang, X. X.; Fu, X.; Estager, J.; Vrinat, M.; Lemaire, M. Ind. Eng. Chem. Res. 2008, 47, 8801-8807.

(99) Sun, Y.; Li, W.; Wang, J. J. Chromatogr. B 2011, 879, 975-980. (100) Schafer, T.; Rodrigues, C. M.; Afonso, C. A. M. Chem. Commun. 2001, 1622-1623.

(101) Dai, Y.; van Spronsen, J.; Witkamp, G. J.; Verpoorte, R.; Choi, Y. H. Anal. Chim. Acta 2013, 766, 61-68. 